\title{
Effect of Gentamicin on the Auditory Brainstem Evoked Response in Term Infants: A Preliminary Report
}

\author{
DAVID KOHELET, MARIAN USHER, ELIANA ARBEL, AHARON ARLAZOROFF, AND \\ MICHAEL GOLDBERG \\ Departments of Neonatology and Neurology, Assaf Harofeh Medical Center, Zerifin and The Sackler School of \\ Medicine, Tel-Aviv University, Tel Aviv, Israel
}

\begin{abstract}
Seven essentially healthy term infants who received gentamicin starting on the 1 st day of life for prolonged rupture of membranes and maternal fever were compared with nine healthy term infants to determine whether this drug induces alterations in the auditory pathway. The auditory pathway was studied on the 3rd day of life by analyzing brainstem auditory evoked potentials elicited by a click stimulus presented at the infant's ears. Latencies of components III and V, interval I-III, and interval $\mathrm{I}-\mathrm{V}$ were significantly prolonged in the gentamicin group, indicating impairment of the central component of the auditory pathway. Peak and trough serum gentamicin levels all fell within the recommended therapeutic range. The study indicates that short course gentamicin therapy in healthy newborn infants can lead to abnormality of auditory function. (Pediatr Res 28: 232-234, 1990)
\end{abstract}

\section{Abbreviations}

BAER, brainstem auditory evoked response

Gentamicin is frequently used in the treatment of suspected or proven neonatal bacterial infection. The major concern with administration of this drug to infants with normal renal function is 8th cranial nerve toxicity. Several cases of ototoxicity in neonates have been reported with the use of this drug $(1,2)$. In those cases in which hearing loss was documented, factors other than gentamicin usage might have caused the damage.

The BAER reflects the electrical events generated within the auditory pathway from the 8th nerve to the diencephalon. Brainstem auditory potentials have been well defined in the newborn infant (3), and several studies indicating its potential value in detecting neurologic disorders in the newborn have been described (4-6). The general principle is that a defect at the level of the 8th nerve will result in a heightened threshold and a prolongation of latency of all potentials, whereas a lesion at the level of the brainstem will result in longer latencies only of those waves originating from structures distal to the lesion.

A prospective study (7) evaluated BAER in 43 preterm infants born at a mean gestational age of $29 \mathrm{wk}$ with multiple risk factors who had received gentamicin for a mean of $14 \mathrm{~d}$.

Mean response latencies of waves I and $\mathrm{V}$ were abnormal in $57 \%$ of the infants. These data suggest the possibility of a disturbance to the auditory system by gentamicin. On the other hand, a study of BAER conducted at the age of at least $5 \mathrm{wk}$ in

Received December 27, 1989; accepted May 2, 1990.

Correspondence: Dr. D. Kohelet, Department of Neonatology, Assaf Harofeh Medical Center, 70300 Zerifin, Israel.
32 term and preterm infants who had been similarly treated with gentamicin failed to demonstrate any association between hearing loss and the administration of this drug (8).

We performed a prospective study investigating auditory function by BAER in the newborn period in term infants receiving gentamicin for prolonged rupture of membranes and maternal fever. Patients with risk factors of auditory pathway disturbances other than gentamicin administration were excluded.

\section{MATERIALS AND METHODS}

Subjects. Sixteen term infants were studied; seven infants composed the gentamicin group and nine infants, the control group. The gentamicin infants were essentially healthy newborns who received gentamicin as a prophylaxis because of premature ruptured membranes and maternal fever. The control group also consisted of healthy newborns drawn at random. These infants had no antecedent premature ruptured membranes and/or maternal fever.

In addition to being clinically normal and healthy at birth, all 16 infants had normal Apgar ratings, normal blood counts, and normal postnatal courses with no clinical or laboratory evidence of infection. Jaundice, when present, was physiologic with maximum serum bilirubin not exceeding $190 \mu \mathrm{mol} / \mathrm{L}$. Table 1 provides selected clinical data on the infants.

Informed parental consent was obtained in all cases before enrollment into the study.

Treatment. All seven infants in the gentamicin group received $2.5 \mathrm{mg} / \mathrm{kg}$ gentamicin every $12 \mathrm{~h}$, starting on the $1 \mathrm{st}$ day of life shortly after birth. The antibiotic was administered for $5 \mathrm{~d}$. Peak serum gentamicin levels were evaluated $30 \mathrm{~min}$ after the 5 th dose on $\mathrm{d} 3$ and trough serum levels were evaluated $30 \mathrm{~min}$ before the 6th dose on $\mathrm{d} 3$.

All peak levels varied from 9.29-16.63 $\mu \mathrm{mol} / \mathrm{L}$ (recommended therapeutic range $8.64-21.60 \mu \mathrm{mol} / \mathrm{L})$ with a mean of $14.04 \pm$ $0.22 \mu \mathrm{mol} / \mathrm{L}$. Trough levels varied from $2.80-4.10 \mu \mathrm{mol} / \mathrm{L}$ (recommended level $<6.48 \mu \mathrm{mol} / \mathrm{L}$ ) with a mean of $3.50 \pm 0.04$ $\mu \mathrm{mol} / \mathrm{L}$.

$B A E R$. BAER was measured in all infants after feeding on the 3rd day of life, using a Microshev neuroscope (Eilon Shvut, Israel). A click stimulus was presented through earphones monaurally at a repetition rate of $10 / \mathrm{s}$. The device was set to $0.2 \mathrm{mV}$ sensitivity and $10 \mathrm{~ms}$ analysis time. Eleven hundred recordings at 115 decibels sound pressure level from each ear were averaged. Six parameters, namely peak latency of components I, III, and $\mathrm{V}$ and interpeak latency of intervals I-III, III-V, and I-V, were measured in $\mathrm{ms}$ and recorded for each ear.

Statistical analysis. For each of the six parameters, mean ear values have been evaluated against mean ear values by the unpaired $t$ test in the gentamicin group as compared with the control group. Pearson correlation coefficient has been used to 
Table 1. Clinical data on studied infants

\begin{tabular}{lcc}
\hline & $\begin{array}{c}\text { Gentamicin } \\
\text { group } \\
(n=7)\end{array}$ & $\begin{array}{c}\text { Control } \\
\text { group } \\
(n=9)\end{array}$ \\
\hline Birth wt $(\mathrm{kg})$ & $3.2 \pm 0.3$ & $3.5 \pm 0.6$ \\
Gestational age (wk) & $39.3 \pm 0.7$ & $40.1 \pm 1.1$ \\
Apgar & & \\
$\quad 1 \mathrm{~min}$ & $8.5 \pm 0.3$ & $8.7 \pm 0.6$ \\
$\quad 5 \mathrm{~min}$ & $9.2 \pm 0.7$ & $9.3 \pm 0.5$ \\
Gender $(\mathrm{M} / \mathrm{F})$ & $5 / 2$ & $5 / 4$ \\
Mode of delivery & 5 & 8 \\
$\quad$ Vaginal & 2 & 1 \\
$\quad$ Abdominal & $139 \pm 9$ & $156 \pm 30$ \\
Peak bilirubin level $(\mu \mathrm{mol} / \mathrm{L})$ & &
\end{tabular}

determine association between gentamicin concentrations (peak and trough) and BAER. All values are presented as mean \pm SD.

\section{RESULTS}

Table 2 indicates the recorded values in each group. In each ear, delayed BAER are demonstrated in five of the six measured parameters in the gentamicin group as compared with the control group. These differences achieved statistical significance in each ear with respect to wave III latency, wave V latency, I-III interval, and $\mathrm{I}-\mathrm{V}$ interval. The III-V interval demonstrated a similar pattern in each ear; however, statistical significance was achieved in the right ear alone. Wave I latency values did not follow the pattern of the other parameters, such differences that were demonstrated did not achieve statistical significance.

The associations between gentamicin levels and latency measurements were insignificant.

\section{DISCUSSION}

Previous studies $(1,2,5,7)$ have indicated auditory function impairment in newborn infants after gentamicin treatment. Most of these infants, however, were very sick, very small prematures with multisystem acute pathology. It is highly likely that the clinical course in these infants was complicated by known insults such as hypoxemia acidosis and poor perfusion. It is, therefore, difficult to ascribe such auditory function impairment to gentamicin alone.

Our findings indicate that, in otherwise healthy term newborn infants receiving gentamicin essentially as a prophylaxis, a short course of the antibiotic can be associated with adverse effects on neurosensory auditory function. This impairment reached statistical significance in five of the six measured parameters.

Gentamicin did affect wave III and wave V "generators" in both lower and upper brainstem. Wave I, arising from the distal portion of the acoustic nerve, was not affected. The findings, therefore, indicate selective impairment of the central brainstem component of the auditory pathway, without involvement of the peripheral nerve.

Such impairment in auditory function as detected in the newborn period may reverse itself, as demonstrated by Adelman et al. (8). This would indicate that recovery is probably the rule, but keep in mind the many risk factors at play and their severity and duration.

The possibility does remain, however, that such transient interference may harbinger future impairment at a later age when language function develops. Therefore, BAER abnormalities, if detected in the newborn period, should alert the physician to the possibility of such development in early childhood.

Acknowledgment. The authors thank R. Giladi for her technical assistance. 


\section{REFERENCES}

1. Bernard PA 1981 Freedom from ototoxicity in aminoglycoside treated infants: a mistaken notion. Laryngoscope 91:1985-1994

2. Elfvig I, Pettay O, Raivio M 1973 A follow-up study on the cochlear, vestibular and renal function in children treated with gentamicin in the newborn period. Chemotherapy 18:141-153

3. Starr A, Amlie RN, Martin WH, Sanders S 1977 Development of auditory function in newborn infants revealed by auditory brainstem potentials. Pediatrics 60:831-839

4. Despland PA, Galambos R 1980 The auditory brainstem response (ABR) is a useful diagnostic tool in the intensive care nursery. Pediatr Res 14:154-158
5. Galambos, R, Despland PA 1980 The auditory brainstem response (ABR) evaluates risk factors for hearing loss in the newborn. Pediatr Res 14:159163

6. Duara S, Suter CM, Bessard KK, Gutberlet RL 1986 Neonatal screening with auditory brainstem responses: results of follow-up audiometry and risk factor evaluation. J Pediatr 108:276-281

7. Cox G, Hack M, Metz D, Fanaroff A 1979 Auditory brainstem evoked responses for screening very low birthweight (VLBW) infants. Effect of gentamicin and neonatal risk factors on maturation. Pediatr Res 13:524A(abstr)

8. Adelman C, Linder N, Levi H 1989 Auditory nerve and brainstem evoked response in infants treated with gentamicin as neonates. Ann Otol Rhinol Laryngol 98:283-286 